\title{
MUDANÇAS NO UNIVERSO DOS QUADRINHOS: textos, materialidades e práticas culturais
}

\author{
CHANGES IN THE COMICS' UNIVERSE: \\ texts, materialities and cultural practices
}

\author{
Marco Antonio de Almeida*
}

\begin{abstract}
Resumo
As mudanças nas tecnologias de informação e comunicação modificaram drasticamente as formas pelas quais se relacionam os textos, seus suportes materiais e as formas de leitura socialmente estabelecidas. Isso implica em refletir acerca das maneiras pelas quais se poderia estabelecer uma "sociologia dos textos" - ou seja, uma reflexão voltada à análise histórica dos processos sociais de produção, circulação e recepção dos textos. Abordaremos essas questões num contexto marcado tanto pela presença cada vez maior das tecnologias de comunicação e informação no cotidiano dos indivíduos, grupos e instituições como pela multiplicação exponencial de textos nos mais diversos suportes, proporcionada pelos processos de digitalização. Uma reflexão que se torna ainda mais complexa quando nos interrogamos acerca dos textos que transcendem o suporte material do livro, socialmente legitimado. Nosso foco abarca o universo das histórias em quadrinhos (HQs), que servirão para ancorar empiricamente as reflexões propostas. Adotamos uma perspectiva que considera que o universo das HQs funciona simultaneamente como uma forma de consumo e de expressão cultural, que se realiza, por meio de diversas modalidades de interação que vão além do puro consumo/leitura dos álbuns e revistas. Essas modalidades podem compreender desde formas de viabilizar a produção artística (plataformas de crowdfunding e crowdsourcing), práticas "piratas", produção e manutenção de sites e blogs autorais de veiculação das obras literárias e HQs produzidas, participação em fóruns de debates e de críticas da produção de $\mathrm{HQ}$, sites de vendas e organização de eventos, uso do youtube, entre outros. Palavras-Chave: Práticas Culturais. Histórias em Quadrinhos. Tecnologias de Informação e Comunicação. Cultura da Convergência.
\end{abstract}

\begin{abstract}
Changes in information and communication technologies have drastically changed the ways in which texts, their material supports and socially established forms of reading are related. This implies reflecting on the ways in which a "sociology of texts" could be established - that is, a reflection on the historical analysis of the social processes of production, circulation and reception of texts. We will address these issues in a context marked by the increasing presence of communication and information technologies in the daily lives of individuals, groups and institutions, as well as by the exponential multiplication of texts in the most diverse media, provided by the digitization processes. A reflection that becomes even more complex when we ask ourselves about the texts that transcend the material support of the book, socially legitimized. Our focus is on the universe of comics (HQs), which will serve to anchor the proposed reflections empirically. We adopt a perspective that considers that the universe of comics works simultaneously as a form of consumption and cultural expression, which takes place, through various modes of interaction that go beyond the pure consumption / reading of albums and magazines. These modalities may include ways of making artistic production feasible (crowdfunding and crowdsourcing platforms), "pirate" practices, production and maintenance of websites and blogs, and the publishing of literary works and comics produced, participation in forums for debate and criticism of production of $\mathrm{HQ}$, sales sites and organization of events, use of youtube, among others.
\end{abstract}

Keywords: Cultural Practices. Comics. Information and Communication Technologies. Culture of Convergence.

\footnotetext{
* Professor/pesquisador do Departamento de Educação, Informação e Comunicação da Faculdade de Filosofia, Ciências e Letras de Ribeirão Preto, da Universidade de São Paulo (FFCLRP-USP); membro do Programa de Pós-Graduação em Ciência da Informação Escola de Comunicações e Artes (ECA-USP), Líder do grupo de pesquisa Práticas Culturais e Tecnologias de Informação e Comunicação (Practict). E-mail: marcoaa@ffclrp.usp.br.
} 


\section{Introdução}

O mundo contemporâneo é resultado, entre outros fatores, da aceleração das mudanças tecnológicas de final do século XIX e decorrer do século XX, marcadas pela multiplicação de suportes da informação: fotografias, microfilmes, cassetes de áudio, rolos de filmes, fitas VHS, CDs, DVDs, até chegarmos aos suportes/repositórios digitais, e às concepções de biblioteca digital. Todos esses processos influenciaram a constituição e a mudança no âmbito da produção, da circulação e da apropriação das formas culturais e do conhecimento (BURKE, 2012; HALL, 1997). Considerando-se esse processo histórico e o contexto social mais contemporâneo, nosso interesse direciona-se para o estudo das relações entre práticas culturais e a maneira pela qual elas são influenciadas pela apropriação da informação e das tecnologias. Nosso ponto de partida é a ideia de uma "cultura da convergência", cunhada por Henry Jenkins (2009) para problematizar questões relevantes em relação às mudanças culturais e sociais, especialmente na maneira pela qual indivíduos e grupos se relacionam com os conteúdos culturais na atual sociedade em rede. Interessam-nos, particularmente, as conexões entre os processos que caracterizam a cultura da convergência e os processos de apropriação cultural e social da informação e dos bens culturais. Esses processos implicam diferentes assimetrias sociais (na distribuição do poder político, do poder econômico e do poder simbólico) e no estabelecimento de diversas táticas e estratégias na utilização das tecnologias.

Mesmo que a ideia de uma cultura da convergência possibilite a descrição de um processo cultural global que implica a apropriação cultural mediada pelas tecnologias, vale lembrar que características e condições decorrentes das especificidades locais influenciam essa dinâmica. Os conteúdos e formatos muito diversos disponibilizados nas redes agregam-se às facilidades proporcionadas pelo formato digital, e "possibilitam a hibridização e a recriação cultural por parte dos indivíduos e grupos, gerando distintas possibilidades de apropriação cultural no âmbito de uma cultura da convergência" (ALMEIDA, 2018, p. 233). Nesse sentido é que Jenkins introduz a figura do prosumer (neologismo oriundo da combinação das palavras produtor e consumidor), partindo da constatação de que os indivíduos na sociedade em rede, com as ferramentas disponíveis, convertem-se também em potenciais produtores de conteúdo. Desse modo, seria estabelecido um ciclo contínuo entre os papéis de emissores e de receptores de mensagens, embaralhando consideravelmente o que tradicionalmente compreendemos como os papéis de usuários e consumidores. Esse novo perfil, potencializado pelas mídias sociais, contribuiria para ampliar a tendência descrita por Chris Anderson (2006) como "cauda longa". Para Anderson, as pessoas passariam a encontrar mais ofertas culturais minoritárias afins aos seus interesses, que em geral não eram satisfeitas pela indústria cultural mainstream. Esse processo alavancaria e sustentaria, em muitos casos, a emergência de efetivas culturas de nicho.

Para abordar estas questões, propomos explorar o universo cultural das Histórias em Quadrinhos (HQs), bem como a comunidade geek (termo que descreve indivíduos interessados 
nas HQs e produtos derivados, como filmes, séries, videogames etc.) que nele se estrutura. Entendemos o universo das HQs como um objeto estratégico do ponto de vista heurístico, ao permitir analisar e problematizar questões tanto de cunho prático como teórico (JENKINS, 2009; ALMEIDA, 2018).

\section{Circulação da informação nas HQs, os fãs e seus nichos}

As Tecnologias de Informação e Comunicação (TICs) marcam presença nas HQs desde seu período clássico, reproduzindo e ao mesmo tempo colaborando para construir o imaginário social a seu respeito. Basta lembrar a origem de clássicos do gênero, na década de 1930, com raízes no imaginário da ficção científica, como Buck Rogers, Flash Gordon e Brick Bradford, ou mesmo personagens de outros gêneros que ostentavam gadgets tecnológicos - o relógio-comunicador de Dick Tracy, a batcaverna de Batman, etc. Isso permitiu aos leitores vislumbrar novas possibilidades de lidar com as informações e também refletir acerca de outros padrões possíveis de sociabilidade, constituindo comunidades de fãs e gerando redes de compartilhamento de informações, opiniões e outras formas de expressão em torno desse universo, a partir dos recursos disponíveis na época. A explosão da internet e a emergência da "sociedade da informação" e de uma "cultura da convergência", com a presença cada vez maior das diversas tecnologias no cotidiano das pessoas, só reforçaram esse fenômeno.

Dentro da indústria cultural, o universo das histórias em quadrinhos, com o avanço dos meios técnicos e dos meios de comunicação através do ciberespaço, vem desenvolvendo produtos e experiências transmídias, que entrelaçam diferentes formas de consumir, participar e produzir produtos, que possuem, entretanto, derivações e características da mídia original. Marcas que representam o mainstream das HQs de super-heróis, como a Marvel e DC reúnem hoje milhões de fãs que se organizam em diferentes tipos de comunidades, ao longo do mundo e do ciberespaço, fãs esses que desenvolvem e empregam diferentes tipos de atividades para desempenhar suas performances, desde a participação e a organização de eventos, cosplays ${ }^{1}$, participação em fóruns ou grupos de redes sociais com os temas que lhe são de interesse, até a produção de novos produtos culturais como fanzines ${ }^{2}$ e filmes que, em muitas vezes, se apropriam dos materiais e informações dos produtos culturais produzidos por essas grandes marcas.

A cultura dos fãs ou Fandom para Jenkins (2009, p. 426) é "um termo utilizado para se referir à subcultura dos fãs em geral, caracterizado por um sentimento de camaradagem e solidariedade com outros que compartilham os mesmos interesses". Por meio de uma cultura

1 Cosplay é uma prática comum nas comunidades relacionadas com a cultura pop, em que os fãs se vestem com os trajes de um personagem que admiram, em alguns casos desempenhando performances de interpretação do personagem.

2 Fanzines: o termo "designa uma revista feitas por aficcionados do gênero, a maioria das vezes colecionadores ou artistas iniciantes. Nesse sentido, a própria palavra escolhida para definir essas publicações já define suas principais características, representando a junção de dois termos: fã e magazine” (VERGUEIRO, 2005, p. 7). 
participativa, esses fandoms remodelam a forma de consumo das mídias através de suas performances (BECKO, 2017), se apropriando dos materiais e criando novos significados. Vergueiro (2005), por exemplo, define cinco tipos de consumidores de histórias em quadrinhos: eventuais, exaustivos, seletivos, fanáticos e estudiosos. Essas definições não são excludentes, e um mesmo consumidor pode se encontrar em mais de uma dessas definições dependendo do material consumido. Jenkins (1992) propõe a concepção de "fãs seguidores", a qual distingue dos "fãs participativos": esses últimos, antes mesmo do surgimento de uma cultura da convergência, já empregavam suas performances exercendo seu papel de fã e se conectando com outros participantes de um mesmo fandom e também de famdoms diferentes, exibindo um comportamento "nômade", se apropriando de novos materiais e significados (BECKO, 2017). Matt Hills e Clarice Greco, por sua vez, refletem acerca das distinções entre fãs, expectadores e audiência para analisar como o consumo regula o investimento emocional nas narrativas culturais - o que seria uma rotina habitual ligada, de alguma forma, aos processos de formação identitária (HILLS; GRECO, 2015). Nesse sentido que acreditamos que as TICs potencializam o acesso a esses conteúdos, tanto para os fãs strictu sensu, como também para os seguidores habituais, eventuais e mesmo esporádicos - poderíamos considerar os fãs como um caso extremo desse gradiente de consumo cultural.

Antes mesmo da disseminação do ciberespaço e do acesso aos meios técnicos necessários para sua utilização, podemos mapear movimentos e práticas que também contribuíram para a validação cultural do campo das histórias em quadrinhos. Na década de 1960, intelectuais e artistas europeus contribuíram para dar um respaldo artístico-cultural às HQs, atribuindolhes um novo status simbólico (MAZZUR; DANNER, 2014). Artistas como Alan Renais, Pablo Picasso, Jean Luc-Godard, Federico Fellini e acadêmicos como Marshall McLuhan, Francis Lacassin, Umberto Eco, Edgar Morin, entre outros, assumiram-se como fãs e admiradores dos quadrinhos, além de estudiosos, quebrando parte do elitismo cultural da época que negava a cultura pop, proporcionando ao universo das HQs ocupar outros espaços, como a academia e os jornais, facilitando que artistas do meio conseguissem publicar histórias mais sérias e densas, diferente do que era produzido até então.

Nessa época, no âmbito norte-americano, ocorria a emergência do movimento underground que, ao contrário do cenário europeu onde as HQs eram defendidas por intelectuais e artistas, organizou-se principalmente contra o controle do Comics Code Authority (CCA), que censurava as histórias em quadrinhos publicadas pelas grandes editoras, limitando certos assuntos como sexo, drogas e questões sociais. Em reação ao CCA, alguns artistas de São Francisco começaram a produzir quadrinhos de forma independente, abordando esses temas e sendo também influenciados por músicos e outros artistas da contracultura que surgiam na época. $\mathrm{O}$ movimento underground norte-americano lutava a favor da liberdade dos autores e contra a passividade da indústria perante a censura do CCA e, nesse período, vários artistas se destacaram e ficaram conhecidos no meio, como Robert Crumb, Gilbert Shelton, Rick Griffin, 
Spain Rodriguez, S. Clay Wilson, entre outros. Embora tenha proporcionado uma revolução no formato, na temática, na produção e na maneira de consumir quadrinhos, seu impacto foi localizado, na medida em que seu "mercado" era tipicamente de nicho, circunscrito às universidades e ao circuito artístico underground (MAZZUR; DANNER, 2014).

No Brasil, um caso que vale destaque é o da Circo Editorial, que foi um contraponto às editoras e às HQs que dominavam o mercado, fugindo do padrão super-heróis/histórias para o público infanto juvenil. Fundada por Toninho Mendes e Chico Caruso, em 1984, foi responsável por algumas das principais publicações em quadrinhos da década de 1980. Sua primeira publicação foi o livro do quadrinista Angeli Chiclete com Banana, Bob Cuspe e Outros Inúteis, seguida de outras revistas como a Circo, Piratas do Tietê, Geraldão e Níquel Náusea, envolvendo contribuições de artistas como Laerte, Glauco, Luiz Gê, Fernando Gonzales, entre outros. Influenciados pelo movimento underground americano e por artistas como Ziraldo, Millôr Fernandes e Henfil que publicaram no jornal Pasquim, as revistas publicadas pela Circo funcionaram como espaço para a republicação de tiras já veiculadas em jornais e outros periódicos na forma de coletâneas, além de permitir aos artistas explorarem novos potencialidades, linguagens e formatos. As dificuldades econômicas decorrentes das reviravoltas do mercado, entretanto, acabaram encerrando as atividades da Circo (SANTOS, 2013).

\section{O mercado ou os mercados? Novas possibilidades para fãs e produtores culturais}

Embora a indústria e as mídias tradicionais ainda hoje representem um grande espaço no oceano informacional que está disponível na rede, o ciberespaço também ofereceu lugar para o nascimento de novas mídias independentes, que remodelaram a lógica do mercado tradicional, forçando a indústria das mídias tradicionais a repensar suas estratégias. Esses aspectos condicionaram o surgimento de novas organizações sociais com a intenção de compartilhar conhecimento dentro do ciberespaço - os fóruns on-line, listas de discussão e blogs, sites e plataformas de financiamento de projetos são frutos desse movimento. $\mathrm{O}$ ciberespaço e a convergência das mídias disponibilizaram novas ferramentas para que essas comunidades introduzissem modelos diferentes dos paradigmas da mídia tradicional de massa que viveu estável durante quase todo o século XX, abrindo possibilidades para a emergência de novas práticas que configuraram um mercado informacional relativamente independente, em que essas comunidades de fãs puderam ocupar um espaço que a mídia tradicional não ofertava.

Essa disseminação do ciberespaço, no qual novas e antigas mídias colidem, alterando suas relações recíprocas de consumo e produção, que Jenkins (2009) descreve como cultura da convergência, processo que também vem redefinindo a forma como se configuram as práticas culturais e a busca e produção de informação na rede. Comunidades participativas, como no caso das comunidades de fãs, podem recombinar novas e velhas práticas de produção de conteúdo, se apropriando de materiais produzidos por outras mídias e/ou produzindo novos materiais 
originais, através dos meios técnicos proporcionados pelo ciberespaço e pelas mudanças nos protocolos sociais e na relação com a cultura popular:

\begin{abstract}
A hipertextualidade, um dos paradigmas da cultura pós-moderna, a ligação das diversas informações e referências, tende a se fortalecer cada vez mais com a libertação dos conteúdos e formatos de seus suportes materiais oferecidos pelas tecnologias digitais. Desenha-se assim um cenário potencialmente libertário, no qual a redistribuição do poder cultural - tanto no plano simbólico como no âmbito da produção - se apresentaria de maneira mais favorável ao pólo popular da esfera cultural (ALMEIDA, 2016, p. 145).
\end{abstract}

Neste cenário, a cultura de nicho encontrou os meios necessários para se fazer representada dentro do cenário informacional, já que na mídia tradicional havia pouco ou nenhum espaço para alguns desses nichos. Dentro de um contexto de comunicação de massa, de mídias tradicionais como a TV, o rádio e o jornal, o controle da informação era feito em grande parte pelos conglomerados de comunicação como a Time Warner, o grupo Bertelsmann, News Corporation, entre outros, que eram responsáveis pelo fluxo de informação global entre as redes de comunicação territoriais (THOMPSON, 1998). Assim, ficava a seu cargo mediar as informações globais transmitidas, junto com outras informações de acordo com os contextos locais. No ciberespaço e na convergência das mídias, esse tipo de controle global da informação deixa de depender exclusivamente desses grandes conglomerados: hoje, com um smartphone, qualquer pessoa potencialmente pode produzir e compartilhar uma informação e publicar em rede social. Dependendo do conteúdo e do engajamento das pessoas e grupos envolvidos com esse material, ele pode atingir alcance global, inclusive sendo reproduzido por veículos da mídia tradicional, ainda que haja alguns dispositivos de mediação dentro da rede, como "filtros invisíveis" dos sites de buscas e as "bolhas filtros" que são construídos com base nos perfis dos usuários (PARISER, 2012; ALMEIDA, 2018).

A abordagem do universo das HQs aqui proposta retoma Almeida (2018), a partir de duas vertentes. A primeira vertente apoia-se na concepção de representação social, particularmente na forma como é empregada por Stuart Hall (2016) para descrever o processo pelo qual os membros de uma cultura utilizam-se da linguagem para produzir sentido e conhecimento. Trata-se de uma abordagem construtivista, que segundo Hall, baseia-se tanto na perspectiva semiótica/semiológica (influenciada por Saussure e Barthes), focada na maneira pela qual os signos produzem sentidos, como na perspectiva discursiva (Foucault), concentrada na maneira pela qual o discurso e as práticas discursivas produzem conhecimentos. A segunda vertente é o já mencionado conceito de "cultura da convergência", com foco nas conexões com os processos de apropriação social da cultura e da informação. Embora formuladas no âmbito do universo das HQs, são questões que incidem nos debates mais amplos acerca das identidades sociais e culturais e suas representações no território dos meios de comunicação (HALL, 1997, 2016; ALMEIDA, 2018). Nesse sentido, ao considerarmos o universo das HQs, estaremos buscando compreender os processos simultâneos 
de consumo e de expressão cultural que o mesmo articula, por meio de diversas modalidades de interação. Modalidades que podem abarcar tanto formas de viabilizar a produção artística (plataformas de crowdfunding e crowdsourcing) como sites e blogs autorais de veiculação das HQs produzidas e de opinião do público acerca delas, participação em fóruns de debates e críticas da produção de HQ, sites de vendas e organização de eventos etc.

Sempre é difícil falar de mercado de HQs no Brasil pela falta de dados consolidados e/ ou abrangentes. A maioria das pesquisas e levantamentos é parcial, cobrindo setores e períodos específicos $^{3}$. Entretanto algumas considerações costumam ser comuns, entre elas as relativas às dificuldades estruturais desse mercado. Um dos grandes gargalos no Brasil diz respeito à distribuição, praticamente monopolizada hoje pela Distribuidora Total, empresa do grupo Abril que há poucos anos incorporou o único concorrente de peso, a Distribuidora Fernando Chinaglia. Com a decadência e possível falência do grupo Abril, somada à diminuição da quantidade de bancas de jornal em todo o território nacional, o circuito tradicional de distribuição e circulação de HQs restringiu-se muito. Por outro lado, a presença das HQs em livrarias e lojas especializadas cresceu bastante no período. Mas aqui o fenômeno da concentração voltou a se repetir, com a FNAC e a Livraria Cultura compartilhando a maior fatia do bolo. Essas grandes livrarias representavam mais de $50 \%$ do faturamento das pequenas e médias editoras. Com a quebra da FNAC, e a absorção de suas dívidas e estoques pela Livraria Cultura - que posteriormente também teve sérios problemas de gestão de dívidas - a situação tornou-se bastante grave. Desse modo, a maior parte das pequenas e médias editoras é hoje refém da Amazon ou tenta encontrar formas alternativas de se viabilizar. Há uma tentativa de estimular a compra de produtos diretamente dos sites das editoras, com descontos, e também articular formas mistas de produção, envolvendo financiamento direto do público com parcerias com plataformas de financiamento como a Catarse.

Apesar dos problemas anteriormente citados, vale considerar uma série de mudanças que ocorreram no mundo das HQs que contribuíram para aumentar sua "legitimidade": a incorporação de conteúdos e linguagens mais "adultas" e sofisticadas; mudanças nos formatos dos suportes (graphic novels e encadernados de luxo com capa dura), aproximando-os do padrão dos livros; a consolidação de circuitos de crítica e premiação. Isso levou a mudanças no status simbólico e na circulação das HQs, que se estendeu das bancas de jornal para as livrarias e lojas especializadas. Houve um boom de publicações, editoras, feiras e encontros com artistas. O nicho ganhou um fôlego extra com o respaldo de eventos enormes, como a FIQ! (Festival Internacional de Quadrinhos!) e a CCXP (Comic Con Experience), que em 2017 teve público recorde de 227 mil pessoas em São Paulo. Numa vertente ainda mais “alternativa”, vale citar a Comic-Con da Favela, como a chamaram seus organizadores, evento que aconteceu na Fábrica de Cultura do Capão Redondo, extremo sul da cidade de São Paulo, com mais de 4 mil

3 Um bom levantamento par a situação do mercado de HQs nas décadas de 1980 e 1990, chegando ao início dos anos 2000, pode ser encontrada em Saks (2015). Para um panorama mais atual, enfocando a internet, ainda que parcial ver Marino (2018). 
participantes que rodaram pelos sete andares do prédio nas nove horas de programação, feita com artistas fora do padrão branco e elitizado que normalmente circulam no espaço nerd - por exemplo, Load Comics e Wagner Loud, dupla que criou e deu vida ao "Rap em quadrinhos", que ilustrou grandes nomes do movimento hip hop (como Negra Li, Eduardo, KL Jay, Emicida, Criolo, Mano Brown, Drik Barbosa, entre outros).

Enquanto o mercado mainstream é pautado principalmente por mangás e HQs de aventuras ou infanto juvenis, o mercado independente possui uma quantidade maior de narrativas denominadas graphic novels, geralmente mais densas e intimistas, muitas delas com contornos autobiográficos (uma das tendências fortes no gênero). Esse perfil não é recente, mas ganhou maior força nos últimos tempos. De um modo geral, o meio digital ainda é mais uma plataforma para conhecer novos autores do que para sustentar a leitura. Além disso, o meio mostrou-se estratégico para alavancar a produção dos autores, caso da plataforma Catarse, responsável por tornar viável boa parte da produção que circula no nicho "independente".

Esse cenário nos convida a formular a hipótese de que o mercado das HQs - apesar de todas as dificuldades relacionadas à publicação física e ao custo elevado de criar um trabalho artístico moldando-se, em larga medida, às práticas culturais de seu público - tem buscado novas saídas. A reconfiguração das relações entre produtores/consumidores de produtos e informações culturais ligadas às HQs, passando por novas estratégias e táticas de apropriação e consumo, tem um forte apoio no uso das tecnologias digitais, bem como das possibilidades abertas pelas redes sociais (ALMEIDA, 2018)

$\mathrm{Na}$ realidade, táticas de consumo e produção marginal que configuravam subculturas próprias já existiam no mundo analógico das HQs - fã-clubes e esquemas de trocas de revistas entre os fãs, convenções, produção de fanzines, entre outras - que constituíam experiências de consumo e produção que definiam um repertório de práticas reunidas por seus praticantes sob o rótulo de fandom (JENKINS, 2009). Esse contexto cultural, que vinculava os fãs entre si e com a indústria cultural, não foi abandonado na transição para o universo digital, sendo remodelado e adaptado às novas possibilidades abertas pelas tecnologias. Vale destacar que esse universo das HQs, de seus produtores e consumidores, também aprendeu com os processos de transformação pelos quais passavam outros universos - em particular, o audiovisual e o musical, com a explosão do MP3 e de aplicativos como o Napster e outros. A indústria das HQs, ao contrário de outros setores da indústria cultural, adotou uma postura relativamente distanciada da atividade dos fãs que digitalizavam, nos mais diversos formatos, coleções inteiras de revistas, restringindo-se a enfrentar um ou outro excesso. Essa "cultura do scan" paulatinamente constituiu um formato próprio, ancorada na divulgação de ferramentas como o CDisplay e de formatos como Comic Book Archive File. Esse processo permitiu consolidar novos padrões de interação e colaboração que influenciariam a própria indústria cultural originária (SILVA; SILVA JÚNIOR, 2012).

O conjunto de práticas hipermediadas de participação e uso colaborativo de ferramentas digitais, por parte das subculturas do meio, modificou o entorno comunicacional do universo 
das HQs. Indo além do que se definiu como "pirataria", a "cultura do scan" consolidou-se como um conjunto de práticas que envolvia um repertório de processos capaz de influenciar as escolhas dos públicos no que dizia respeito ao acesso, seleção, leitura e aquisição comercial das produções. Esse último caso, a aquisição comercial, pode parecer deslocado em relação aos demais, mas ilustra as relações ambíguas entre fãs e indústria cultural: trata-se de um conjunto de práticas que se desenvolveu tanto em oposição como em "colaboração". O mote "gostou? compre!", veiculado em muitos scans indicava a vinculação através do consumo, ao mesmo tempo que reconhecia indiretamente uma contrapartida implícita de sua expressão periférica à matriz da indústria cultural (SILVA; SILVA JÚNIOR, 2012).

Escapando do controle dos fluxos de informação, algumas comunidades de fãs encontraram no ciberespaço um terreno fértil para que eles pudessem atender às demandas por informações que não eram ofertadas pela mídia de comunicação de massa. Um exemplo dessas mudanças no Brasil no campo dos quadrinhos foi o caso da revista Wizard Brasil, publicada pela primeira vez entre 1996 e 1997 pela editora Globo, editada por Leandro Luigi Del Manto, sendo cancelada em sua $15^{\circ}$ edição. Após o cancelamento da revista, Del Manto, junto com Sérgio Codespoti, Maurício Muniz e Edson Diogo criaram o site Área-51, para produzir informações sobre quadrinhos e cultura pop. A Wizard Brasil teve mais uma edição publicada em 2001 pela editora Hangar 18, também editada por Del Manto, até ser publicada pela editora Panini entre 2003 e 2006 quando, por motivo de um processo judicial com a empresa de idiomas homônima Wizard, a revista teve de alterar seu nome para Wizmania, mantendo-se até 2009, quando foi cancelada no número 11 de segunda série de tiragens.

O caso da Wizard Brasil demonstra como um grupo de fãs, como o próprio Del Manto e seus colaboradores, percebe que a mídia tradicional não atende à demanda informacional de seus interesses, e que no ciberespaço eles podem construir seu próprio espaço e compartilhar informações e materiais com outros membros da comunidade de fãs e aficionados. Este caso também demonstra o comportamento nômade descrito por Jenkins (2009), já que, quando houve uma oportunidade da indústria para que Del Mano voltasse a produzir a revista, ele retomou suas atividades em outra editora.

Desde então o mercado informacional de quadrinhos na rede só tem crescido, distribuído por diferentes meios de comunicação como texto (blogs, sites, fóruns), áudio (podcasts) e vídeos (Youtube, Twitch). A razão para o crescimento do mercado informacional de quadrinhos no ciberespaço está na própria busca dos integrantes das comunidades de fãs por informações de seu interesse $e^{4}$. De um modo geral, essas produções (especialmente os vídeos do Youtube) compreendem informações e comentários sobre futuros lançamentos do mercado editorial

\footnotetext{
4 Becko (2017), que investigou de que formas os fãs constroem suas performances e como elas contribuem para suas narrativas identitárias no campo das HQs, verificou que dos 876 que responderam à pesquisa, $72 \%$ afirmaram que acompanham "frequentemente" e "sempre" sites, fanpages, blogs, canais no Youtube, entre outros, que falam sobre temáticas relacionadas à cultura nerd, e 65\% das respostas indicaram que acompanham três ou mais desses veículos de informação (BECKO, 2017, p. 6).
} 
de quadrinhos, cobertura de eventos especializados, entrevistas com profissionais da área, discussões sobre as HQs e temas relacionados (por exemplo, séries/filmes baseados em HQs), resenhas e indicações sobre materiais já publicados. Alguns desses canais, assim como aqueles dedicados à literatura de modo mais amplo, passaram a receber materiais lançados pelo mercado, "ocupando em boa parte nesse sentido o papel de mediação cultural que cabia às redações do jornalismo tradicional, destacando-se ainda por conseguirem estabelecer apoios e até parcerias comerciais para a manutenção dos custos que acabam tendo" (SILVA; OLIVEIRA, 2018, p. 2). Com o crescimento desse mercado, novas demandas informacionais foram se desenvolvendo dentro dessas comunidades de fãs, assim como a própria mídia das histórias em quadrinhos - que possui uma variedade de temas e gêneros diferenciados, podendo ser identificados com diferentes grupos e com diferentes interesses em relação à própria mídia, apresentando diversas representações sociais dentro desse meio.

No que diz respeito às modalidades de viabilização do consumo de HQs e da produção artística por meio das tecnologias digitais, podemos considerar que esse mercado ainda está em desenvolvimento no Brasil. Surgiram plataformas como a Social Comics e a Catarse, voltadas a propiciar suporte para os quadrinhistas desenvolverem seus trabalhos através de alguma forma de financiamento em troca de benefícios para os que ajudam os projetos lá cadastrados. A Social Comics é uma plataforma semelhante ao Netflix, mas voltada para as HQs digitais, na qual os usuários pagam uma taxa de assinatura para ter à sua disposição um acervo de quadrinhos bem variados. Na perspectiva do quadrinista, a vantagem está em inscrever-se como alimentador do acervo sem nenhuma taxa. $\mathrm{O}$ incentivo financeiro retorna de acordo com a performance do trabalho do artista no aplicativo: cada vez que uma página é lida por um assinante, é contabilizada para o seu autor no âmbito da plataforma e, assim, monetizada. Apenas as obras ativas no catálogo são passiveis de monetização e computadas, permitindo ao autor saber exatamente quantas pessoas leram sua história, se ela foi lida na íntegra ou parcialmente, permitindo-lhe definir estratégias relacionadas ao seu público e ao seu produto. A Catarse, por sua vez, é uma plataforma de crowdfounding, ou financiamento coletivo, que serve para diversos tipos de projetos e oferece contrapartidas ao público que colabora, com um foco maior na produção de HQs impressas. No início de seu funcionamento, a plataforma possuía um mecanismo de avaliação dos projetos, contemplando sugestões para os proponentes, mas que foi deixado de lado com o crescimento do site. Como "compensação", alguns dos artistas acabam compartilhando suas experiências via internet com dicas e sugestões para os novatos (ALMEIDA, 2018).

Ao serem apropriadas a partir de outras perspectivas, essas plataformas trouxeram alguns benefícios indiretos, já que alguns artistas embutem nos custos do produto despesas com a própria manutenção e outros gastos, gerando uma remuneração própria no período de realização do projeto. Editoras menores, alternativas ou independentes, aproveitaram a oportunidade para associar-se aos artistas e se utilizaram da Catarse para cobrir parte dos custos 
do processo, como a distribuição, por exemplo, concentrando-se em outros aspectos, como a editoração e a impressão. A Catarse, em alguma medida, acabou por gerar um público cativo de apoiadores, que consideram apoiar os artistas "independentes" como um valor em si, investindo nos projetos apresentados no site, por gosto ou “ideologia” (ALMEIDA, 2018).

De qualquer modo, os artistas e produtores dos projetos acabam tornando-se reféns dos algoritmos, que refletem quem é mais visto e quem possui mais chances de ser "visualizado", aspecto acentuado quando os projetos estão vinculados às redes sociais (particularmente, o Facebook) para sua divulgação. Percebe-se, nesse caso, o efeito apontado por Pariser (2012) de "bolha de filtros", a série de mediações que filtra as informações que chegam aos consumidores/ usuários, baseadas em suas preferências e interações e controladas pelos algoritmos. Essas "escolhas" dos algoritmos passam a influenciar o alcance da divulgação dos projetos. Tal tendência ao encapsulamento seria previsível numa "cultura de nicho", retomando Anderson (2006), mas hoje é ainda mais acentuada. As próprias empresas que gerem essas redes sociais reforçam essa situação, como, por exemplo, a política de pagamento para impulsionar postagens, promovida pelo próprio Facebook.

\section{A questão da representatividade e a sociabilidade mediada pelas HQs}

Conforme o mercado informacional de histórias em quadrinhos foi se expandindo, questões como a da representatividade de grupos sociais dentro desse universo foram surgindo à tona. Em um primeiro momento, essas questões foram levantadas em relação às próprias publicações da indústria de quadrinhos, principalmente no mercado americano de super-heróis, e como algumas "minorias" não eram ou eram pouco representadas nas histórias publicadas. Num segundo momento, essas questões foram levantadas no âmbito da indústria, de como há pouco espaço para as minorias na produção e nas premiações dos eventos da área de quadrinhos. No caso brasileiro, um breve olhar sobre as plataformas de financiamento coletivo permite perceber que há um número significativo de produções que possuem uma temática relacionada ao universo feminino e/ou às questões étnicas presentes nessas duas plataformas. Nesse sentido, uma hipótese que podemos considerar é a de que as facilidades proporcionadas pelos usos das TICs, em especial nas redes sociais, abriram perspectivas para uma maior representatividade do público em geral, quebrando o modelo hegemônico do tradicional tipo de leitor de HQ homem branco, jovem e heterossexual - introduzindo temas como o feminismo, o racismo, a homossexualidade e a transsexualidade, entre outros, que passaram a "incomodar" uma parcela desses leitores tradicionais e geraram um conjunto de debates e polêmicas em fóruns, chats, comentários de sites e páginas da internet, que movimentaram esse ambiente cultural.

Para demonstrar a importância que as questões de representatividade assumiram no campo dos quadrinhos, e como as mídias no ciberespaço se tornaram peças fundamentais na disseminação da informação, vale relatar o caso exemplar do Comicsgate. Em julho de 2017, 
várias mulheres que trabalham com a Marvel se reuniram para homenagear Flo Steinberg, icônica editora da indústria de HQs, com importante participação na própria Marvel, e que falecera recentemente. Heather Antos, uma das editoras da Marvel na época, publicou uma foto bebendo milkshake junto com a equipe na rede social Twitter. O que seria uma simples selfie de um momento de celebração se tornou o estopim do que viria a ser o Comicsgate. Após a postagem, algumas pessoas atacaram Antos, argumentando que a foto postada simbolizava tudo aquilo que estava de "errado" na Marvel. No entanto alguns fãs também saíram em defesa dela, levantando a hashtag \#MakeMineMilkshake. Mais tarde, nesse mesmo ano, o grupo responsável pelo ataque assumiu o nome de Comicsgate, para boicotar a diversidade nos quadrinhos, e começou a circular no Twitter uma "lista negra", com nomes de artistas cujas obras deveriam parar de ser consumidas - em sua grande maioria, artistas mulheres, de diferentes etnias ou com posicionamento político de esquerda. A razão alegada para justificar esse boicote, segundo os seguidores do Comicsgate, é de que a diversidade nas HQs seria o motivo das baixas vendas da indústria.

Esse foi o primeiro dos desdobramentos que o caso Comicsgate gerou na indústria e nas comunidades de fãs de histórias em quadrinhos: outros casos de ataques e assédios ocorreriam com artistas e outras pessoas envolvidas no meio, provocando também reações, como os casos de figuras importantes que se posicionaram a favor da diversidade nos quadrinhos ${ }^{5}$. No Brasil, sites como Jamesons, Minas Nerds, Nebulla, entre outros, publicaram matérias cobrindo o caso e divulgando suas repercussões, demonstrando como as questões sobre representatividade e diversidade têm se tornado um dos principais temas de discussão no campo dos quadrinhos e, nesse cenário, a mídia independente de HQs voltada para essas questões está ganhando cada vez mais destaque.

Messias e Crippa (2017) citam o exemplo do site Lady's Comics como uma iniciativa de mediação no Brasil, o site disponibiliza um banco de dados com registros de 62 quadrinistas mulheres, com espaço destinado a divulgar seus trabalhos e informações profissionais, o site também “(...) tem objetivos ligados à memória de trabalhos de mulheres que, historicamente, foram silenciados ou não adquiriram o mesmo status que as produções masculinas no mercado editorial” (MESSIAS; CRIPPA, 2017, p. 8). O Lady's Comics também produzia matérias

\footnotetext{
5 Um ano após o início dessa onda provocada pelo Comicsgate, alguns de seus seguidores assediaram Marsha Cook, viúva do quadrinista Darwin Cook que faleceu em 2016. Em resposta a um usuário que publicou um vídeo de Darwin no Twitter, sugerindo que se estivesse vivo ele apoiaria o Comicsgate, Marsha disse que podia garantir que Darwin pensaria que eram os "idiotas" desse movimento que estariam estragando os quadrinhos. Sua resposta gerou diversas respostas dos seguidores pró-Comicsgate, alguns duvidando que ela fosse a viúva de Darwin, outros criticando seu envolvimento com o assunto. Mas essas respostas também atraíram a atenção de artistas e profissionais da indústria de quadrinhos. Alguns dias após as postagens envolvendo Marsha e Darwin Cook, o escritor Tom Taylor, que escreve histórias tanto para a DC quanto para Marvel, postou uma mensagem em seu Twitter dizendo que os quadrinhos eram para todos, e que não havia espaço para assédio e para preconceitos. Seguindo seu exemplo, outros artistas da indústria também compartilharam suas mensagens em favor da diversidade, nomes como Magdalene Visaggio, Jody Houser, Kelly Thompson, Tim Seeley, Margaret Stohl, Tini Howard, Bill Sienkiewicz, Greg Pak, Fabian Nicieza, Benjamin Percy, Jeff Lemire, entre outros.
} 
e especiais geralmente discutindo as questões voltadas à representatividade feminina nos quadrinhos, discussões que, com o crescimento do acesso ao site, saíram do ciberespaço e se materializaram em dois eventos, o $1^{\circ}$ e $2^{\circ}$ encontro Lady's Comics, o primeiro em 2014 e o segundo em 2016, todos em Belo Horizonte. O site também possuía um canal no Youtube com vídeos de discussões e palestras alinhadas com o mesmo objetivo do site. Em janeiro de 2018, foi publicado post de despedida, segundo as autoras Mariamma e Samara, o projeto estava sendo encerrado por motivos pessoais e de trabalho das autoras por trás do site, mas seu acervo e conteúdo continuam disponíveis para acesso.

As redes sociais também se tornaram parte da extensão dos sites informacionais de quadrinhos. Almeida, Cruz e Oliveira (2018) apresentam a relação que os sites Lady’s Comics, Minas Nerds e Delirium Nerd têm com suas redes sociais e como algumas polêmicas culturais repercutiram entre os seguidores das páginas citadas; os três sites têm como principal tema de discussão a representatividade feminina nos quadrinhos e outras questões envolvendo diversidade. Em um primeiro momento, foram mapeados os temas principais das polêmicas culturais publicadas, no qual três se destacaram: prêmios e eventos, problemas de representação da mulher e contribuição das mulheres para o mundo nerd.

No primeiro grupo temos uma mudança nas chamadas dos textos: o foco inicial, que era sobre a falta de mulheres, polêmica de grande repercussão constante em todos os blogs analisados, deslocou-se para os relatos sobre os boicotes aos prêmios sem indicações femininas, para enfim evidenciar o destaque que foi dado para as mulheres em alguns desses prêmios e eventos. Essa progressão já nos leva ao último grupo supracitado, uma vez que por meio da divulgação destas defasagens de representatividade foi possível uma mudança significativa no meio, da mesma forma podemos notar o aumento de quadrinhos feitos total ou parcialmente por mulheres nos últimos anos" (ALMEIDA; CRUZ; OLIVEIRA, 2018, p. 10).

Em um segundo momento, observou-se as reações dos seguidores em relação às polêmicas publicadas por esses sites em suas redes sociais. De acordo com os autores, existe um engajamento na discussão das polêmicas culturais por parte da comunidade que acompanha esses veículos, nos comentários de publicações feitos na rede social Facebook, os seguidores expressam suas opiniões e posicionamentos em relação aos temas apresentados. Alguns exemplos de temas que geraram estas respostas, são "Síndrome de Arlequina: o perigo por trás da identificação com a personagem!", “7 dicas para não sexualizar uma heroína em HQs" e "Racebending, nerds e racismo".

Assim como os sites citados, nos últimos anos outras iniciativas foram criadas para se discutir questões de representatividade e fornecer um espaço para que participantes da comunidade de fãs de quadrinhos encontrassem materiais desse campo vinculados com seus interesses representacionais e, da mesma forma que esses sites, essas iniciativas têm expandido seus alcances nos diferentes meios de comunicação dentro e fora do ciberespaço. Aqui é 
interessante levantar outra hipótese: a de que essas iniciativas de sites informacionais têm encontrado, nos diferentes meios de comunicação disponíveis no ciberespaço, uma maneira de ampliar seu alcance e de produzir novas iniciativas que colaborem para a visibilidade das questões representacionais nos quadrinhos.

Um bom exemplo nesse sentido, que constitui uma referência importante no Brasil, é o já referido coletivo MinasNerds (criado em 2015), que agrupa mais de mil mulheres, com uma organização empresarial e em pleno crescimento. O coletivo vinculou ou participou de diversas polêmicas relacionadas ao sexismo no meio HQ. Criado especialmente por e para mulheres, a fim de discutir seus hobbies, surgiu na cena geek como um grupo de Facebook voltado para HQs, cosplays, games, literatura, música, cinema e séries de TV. O crescimento do MinasNerd levou à criação de um site e possibilitou perceber a diversidade e riqueza do universo geek feminino. Por outro lado, ao mesmo tempo vieram à tona relatos de abusos, perseguições, misoginia, sofridos no dia a dia pelas mulheres, e de como eram deixadas à margem desse nicho de mercado e grupo de interesse, um reduto tradicionalmente masculino.

As polêmicas envolvendo a premiação dos Troféus HQMIX, no Brasil, em 2015, e a seleção dos indicados para o prêmio do Festival de Angoulême, na França, em 2016, estão entre as questões de gênero que mais foram assuntos das redes e blogs do segmento. Em relação ao HQMIX, foram feitas críticas à publicidade do evento, considerada machista, do mesmo modo como se questionou a representação feminina no prêmio: apenas 13\% das publicações indicadas eram de autoria de mulheres e muitas categorias importantes nem mesmo possuíam alguma mulher indicada. A 43a edição do Festival Internacional de Quadrinhos de Angoulême, um dos eventos mais importantes na área, reproduziu situação semelhante: a lista de 30 nomes indicados para o prêmio não incluía uma única mulher. Após polêmica e boicote de artistas, a direção do evento inicialmente divulgou que iria acrescentar mulheres à lista, posteriormente, novo comunicado mudou completamente os rumos da premiação: ninguém foi indicado. Artistas e membros da entidade (assim como todos que tiveram seus trabalhos publicados naquele ano na França) foram convidados a votar em quem desejassem indicar para o "Grand Prix" - o prêmio mais importante, que coroa, em retrospectiva, um artista e toda sua obra (ALMEIDA, 2018).

Abordagens étnicas também tiveram bastante presença nessas polêmicas, ganhando mais espaço, tanto na indústria mainstream como nos circuitos independentes e alternativos. Temas como os direitos dos negros, a herança da escravidão e as políticas de afirmação, destacando a construção de imagens de empoderamento e afirmação vinculadas às populações negras, foram contemplados nas discussões e nas produções dos artistas. O herói negro das HQs Marvel Comics, o Pantera Negra, foi roteirizado pelo escritor e ativista Ta-Nehisi Coates, sendo posteriormente adaptado para o cinema, com estrondoso sucesso. $\mathrm{O}$ caso de outro personagem da mesma editora, Miss Marvel, demonstra que outros grupos também obtiveram atenção do mainstream. Sob a identidade secreta de Kamala Kahn, uma adolescente muçulmana de ascendência paquistanesa, as principais dificuldades da heroína não surgem do confronto 
com supervilões, mas de lidar com as dificuldades sociais e culturais decorrentes de sua origem familiar e religiosa. Marcelo D'Salete e André Toral propõem releituras da escravidão e de outros episódios da história brasileira em seus trabalhos. Até o site de uma tradicional organização não governamental de ativismo no combate ao racismo e em prol dos direitos afirmativos da população negra, como o Geledés, contempla a presença de uma seção especificamente dedicada às informações e discussões sobre HQs, sinalizando a importância e a representatividade que essa produção cultural atingiu (ALMEIDA, 2018).

\section{Considerações finais}

Para analisar o conjunto de questões levantadas anteriormente em relação a esse universo das HQs, consideraremos a perspectiva de Hjarvard (2014), para o qual o mundo passa por uma midiatização intensa da cultura e da sociedade. Hjarvard compreende as mídias como estruturas que condicionam e permitem a ação humana reflexiva e propõe analisar seu papel em vários contextos sociais, ancorando a teoria da midiatização na teoria social geral. O seu entendimento da midiatização compartilha um território comum com a noção de "mediação", ao deslocar o foco da mídia individual para o papel da mídia na interação social e na mudança cultural.

Podemos entender as indústrias culturais e seus sistemas de mídia como organizações que atuam na seleção, na formatação e na distribuição de bens informacionais, sejam eles músicas, textos, imagens, informações transformadas em notícias etc. Essas atividades implicam o controle do acesso aos bens imateriais e seus suportes e canais de exibição/transmissão. Em larga medida, podem ser descritas como indústrias da intermediação - o que não implica desconsiderar a importância do receptor e das mediações no processo comunicativo. Podemos conectar isso às observações de Jenkins (2009) e refletir como no atual contexto a midiatização e as mediações correlacionadas poderiam possibilitar o direito das pessoas comuns de contribuir ativamente com a sua cultura, ampliando as possibilidades de participação, ainda que com diferentes graus de influência e reconhecimento social.

No caso das práticas culturais que se desenvolvem no âmbito das culturas de nicho, podemos intuir processos de consolidação de novas formas de habitus que se expressam em práticas culturais periféricas, táticas de apropriação relacionadas a formas de colaboração horizontal, que devem ser consideradas quando relacionadas à apropriação social das novas tecnologias. A disseminação ativa de conteúdos implica que suas funcionalidades já se alinham, em alguma medida, com um conjunto pré-definido, mas não necessariamente sistematizado, de normas linguísticas e culturais - um novo habitus em formação. O reconhecimento dessas conexões afirma os conhecimentos culturais em questão, reforçando as bases de apoio que sustentam as práticas e nas quais elas se assentam, formatando e legitimando os atos de recepção como atos de produção cultural, na perspectiva de constituição dos prosumers, segundo Jenkins (2009). 
Ao considerarmos as práticas culturais disseminadas pelo mundo das HQs - formas alternativas de acesso, de viabilização de produções e de sua circulação, da introdução de novas temáticas e de novos protocolos de leitura para as antigas produções -, encontramos sintonia com as observações de Jenkins, quando ele assinala que uma das marcas da convergência das mídias tem sido o deslocamento dos conteúdos produzidos/disseminados por uma cultura midiática na direção de outros suportes e de novas perspectivas de acessibilidade mediante o estabelecimento de relações mais complexas entre as interfaces/produtos e a manifestação participativa de suas audiências. Ao refletir acerca da cultura do fandom, percebe-se a mudança da concepção de participação para um viés mais ativo, de interação e produção ativa no âmbito das mudanças provocadas pelas tecnologias, na passagem de:

\begin{abstract}
uma subcultura particular para um modelo mais amplo que engloba muitos grupos que estão adquirindo maior capacidade de comunicação dentro de uma cultura em rede, e rumo a um contexto em que a produção cultural de nicho está cada vez mais influenciando o formato e a direção da mídia mainstream (JENKINS; GREEN; FORD, 2014, p. 64).
\end{abstract}

Ou seja, os papéis desempenhados pelos diversos atores estão cada vez mais complexamente entrelaçados, embaralhando inclusive as perspectivas sobre adesão ou resistência cultural. Ou, como observam os autores, "estamos passando da celebração do crescimento de oportunidades de participação para uma perspectiva ponderada pela atenção aos obstáculos que impedem muitas pessoas de exercer uma participação significativa” (JENKINS; GREEN; FORD, 2014, p. 65).

Podemos, finalizando, aventar a hipótese de que a apropriação das TICs pelos sujeitos reconfigura osterritórios de convivência e potencializa osencontros. Aumentou significativamente nos últimos anos não só a presença geek/nerd na internet, mas em diversas situações de encontros presenciais: reuniões de fãs-clubes, convenções, feiras, eventos de cosplay. No universo das HQs, exemplar da cultura geek/nerd, objetos e produtos culturais são valorizados a partir de sua capacidade de comunicar. Essa vivência do consumo cultural fundamenta-se em relações de significação e representação, referindo-se ao mundo e nele marcando lugares de memória e identidade. Nesse sentido, valoriza profundamente a catalogação (curadoria) dos bens e produtos culturais, gerando uma necessidade contínua de informação sobre os mesmos. De um modo geral, o conjunto de textos e bens consumidos, bem como sua catalogação e hierarquização, assinalam sua importância na constituição de escolhas de identidade/identificação. São essas escolhas que inserem os indivíduos em grupos ou subgrupos dentro desse universo cultural, construindo lugares no mundo refletidos em estilos de vida e consumo cultural.

A existência e expansão desse tipo de cultura, com fortes traços juvenis, mas não só, fortemente dedicada ao consumo, catalogação e atribuição de sentido aos bens e textos da cultura da mídia, tornou-se possível principalmente graças à penetração das TICs no cotidiano. Há um impulso de compartilhar experiências entre os frequentadores desse universo, que não descarta, 
por outro lado, a exploração do potencial econômico desses eventos: as editoras de HQs, assim como outras indústrias culturais relacionadas, também têm investido fortemente nesse setor. De todo modo, a internet, em particular as redes sociais, são o epicentro organizacional e referencial que possibilita a realização desses encontros na atual escala, funcionando também como feedback para a avaliação, crítica e continuidade dessa prática cultural.

Acredito que as práticas observadas em relação ao universo das HQs encontram similaridades em outros territórios culturais. A apropriação dos recursos e interstícios proporcionados pela internet, no que tange à geração de formas, conteúdos e identidades, proporciona a emergência de repertórios culturais híbridos, que misturam práticas tradicionais e inovadoras, institucionalizadas e não institucionalizadas, legais e "marginais". Por outro lado, as indústrias culturais e seus braços na internet também atentam para esses processos, procurando se aproveitar deles e, no limite, controlá-los. Tornou-se perceptível, para elas, a necessidade de serem capazes de criar novas necessidades a partir da percepção de como são os fluxos de interesse das pessoas que possuem cada vez mais opções disponíveis para seguir: "a captura das atenções é uma arte, mas uma arte tecnológica, baseada na análise dos comportamentos, na definição de padrões comportamentais dos segmentos e indivíduos em rede" (SILVEIRA, 2016, p. 18). Seguindo o raciocínio de Silveira, as plataformas de comunicação on-line tornaramse as mediadoras das ofertas culturais na busca por seus consumidores, buscando modular o comportamento e as escolhas das pessoas por meio dos algoritmos. Nesse sentido, a internet hoje é talvez o front mais ativo da guerra cultural.

\section{Referências}

ALMEIDA, Marco Antonio de. Práticas infocomunicacionais e mediações na cultura da convergência. Revista do Centro de Pesquisa e Formação do SESC, São Paulo, n. 7, p. 228-242, 2018.

ALMEIDA, Marco Antonio de. Processos culturais \& Convergências tecnosociais. Revista do Centro de Pesquisa e Formação do SESC. São Paulo, n. 2, p. 142-158, 2016.

ALMEIDA, Marco Antonio de; CRUZ, Ananda Santos; OLIVEIRA, Diego Tomaz de. As HQs como geradoras de polêmicas - reflexões exploratórias sobre representações sociais. In: JORNADAS INTERNACIONAIS DE HISTÓRIAS EM QUADRINHOS, 5., 2018, São Paulo. Anais da 5a Jornadas Internacionais de Histórias em Quadrinhos. São Paulo: Universidade de São Paulo, 2018. Disponível em: <http://www2.eca.usp.br/jornadas/anais/5asjornadas/q_midia/marco_et_al.pdf>. Acesso em: 24 jun. 2019.

ANDERSON, Chris. Cauda longa: do mercado de massa para o mercado de nicho. Rio de Janeiro: Elsevier, 2006. BECKO, Larissa Tamborindenguy. Desvendando o fã de personagens de histórias em quadrinhos: uma reflexão sobre a cultura de fã, práticas de consumo e performance. In: JORNADAS INTERNACIONAIS DE HISTÓRIAS EM QUADRINHOS, 4., 2017, São Paulo. Anais da 4a Jornadas Internacionais de Histórias em Quadrinhos. São Paulo: Universidade de São Paulo, 2017. Disponível em: <http://www2.eca.usp.br/jornadas/anais/4asjornadas/ q_h_cultura/larissa_becko.pdf>. Acesso em: 24 jun. 2019.

BURKE, Peter. Uma história social do conhecimento: da enciclopédia à Wikipedia. Rio de Janeiro: Zahar, 2012. CERTEAU, Michel de. A invenção do cotidiano: artes de fazer. Petrópolis: Vozes, 1994. 
HALL, Stuart. A centralidade da cultura: notas sobre as revoluções culturais do nosso tempo. Educação \& Realidade, Porto Alegre, v. 22, n. 2, p. 15-46, 1997.

HALL, Stuart. Cultura e Representação. Rio de Janeiro: Ed. PUC-Rio; Apicuri, 2016.

HILLS, Matt; GRECO, Clarice. O fandom como objeto e os objetos do fandom. Revista MATRIZes, São Paulo, v. 9, n. 1, p. 147-163, 2015.

HJARVARD, Stig. A midiatização da cultura e da sociedade. São Leopoldo: Ed. Unisinos, 2014.

JENKINS, Henry. Cultura da Convergência. São Paulo: Editora Aleph, 2009

JENKINS, Henry. Textual Poachers. New York: Routledge, 1992.

JENKINS, Henry; GREEN, Joshua; FORD, Sam Cultura da conexão. São Paulo: Aleph, 2014.

MAZUR, Dan; DANNER, Alexander. Quadrinhos - História moderna de uma arte global. São Paulo: Martins Fontes, 2014.

MARINO, Dani. O Mercado de Quadrinhos Digitais no Brasil em Números. MinasNerds, 21 mar. 2018. Disponível em: http://minasnerds.com.br/2018/03/21/o-mercado-de-quadrinhos-digitais-no-brasil-em-numeros/ Acesso em: 24 jun. 2019.

MESSIAS, Carol Ito; CRIPPA, Giulia. Histórias em quadrinhos na internet como fontes de informação. In: ENCONTRO NACIONAL DE PESQUISA EM CIÊNCIA DA INFORMAÇÃO, 18., 2017, Marília. Anais do XVIII Encontro Nacional de Pesquisa em Ciência da Informação. Marília: Unesp, 2017. Disponível em: <http://hdl. handle.net/20.500.11959/brapci/104693 >. Acesso em: 26 jun. 2019.

PARISER, Eli. O filtro invisível: o que a internet está escondendo de você. Rio de Janeiro: Jorge Zahar, 2012.

SAKS, Danilo do Canto Oliveira. Reações das Editoras Brasileiras de Quadrinhos frente aos cenários de instabilidade econômica. In: JORNADAS INTERNACIONAIS DE HISTÓRIAS EM QUADRINHOS, 3., 2015, São Paulo. Anais da 3a Jornadas Internacionais de Histórias em Quadrinhos. São Paulo: Universidade de São Paulo, 2015. Disponível em: http://www2.eca.usp.br/jornadas/anais/3asjornadas/artigos.php?artigo=artigo_090620151634422. pdf Acesso em: 21 jun. 2019.

SANTOS, Roberto Elíseo dos. O. As mentes por trás da Circo Editorial uma trajetória pelos anos 1970 e 1980 . In: JORNADAS INTERNACIONAIS DE HISTÓRIAS EM QUADRINHOS, 2., 2013, São Paulo. Anais da 2a Jornadas Internacionais de Histórias em Quadrinhos. São Paulo: Universidade de São Paulo, 2013. Disponível em: <http:// www2.eca.usp.br/jornadas/anais/3asjornadas/artigo_290520150919312.pdf>. Acesso em: 24 jun. 2019.

SILVA, Alexandre Honório da; SILVA JÚNIOR, José Afonso. HQs em Convergência: subculturas do consumo e a manifestação colaborativa de uma mídia que espera sobreviver ao digital. Intexto, Porto Alegre, n. 27, p. 102-115, dez. 2012.

SILVA, Heitor da Luz; OLIVEIRA, Gabriel Duarte de. O nicho da produção de conteúdo para audiovisual sobre quadrinhos no Youtube: estudo de caso do Pipoca \& Nanquim. In: JORNADAS INTERNACIONAIS DE HISTÓRIAS EM QUADRINHOS, 5., 2018, São Paulo. Anais da 5a Jornadas Internacionais de Histórias em Quadrinhos. São Paulo: Universidade de São Paulo, 2018. Disponível em: <http://www2.eca.usp.br/anais2ajornada/anais5asjornadas/q_comunicacao/heitor_gabriel.pdf>. Acesso em: 24 jun. 2019.

SILVEIRA, Sergio Amadeu da. Economia da intrusão e modulação na internet. Liinc em Revista, Rio de Janeiro, v. 12, n. 1, p. 17-24, mai. 2016.

THOMPSON, John Brookshire. A mídia e a modernidade: uma teoria social da mídia. Petrópolis: Vozes, 1998 VERGUEIRO, Waldomiro. Histórias em quadrinhos e serviços de informação: um relacionamento em fase de definição. DataGramaZero, João Pessoa, v. 6, n. 2. abr. 2005. 


\section{Sites/Canais do Youtube:}

Catarse. Disponível em: https://www.catarse.me

Delirium Nerd. Disponível em: https://www.facebook.com/delirium.nerd

Geledés-HQ. Disponível em: https://www.geledes.org.br/tag/hq/\#gs.LbFw8

Lady’s Comics. Disponível em: http://ladyscomics.com.br/

Minasnerds: Disponível em: http://minasnerds.com.br/

Social Comics. Disponível em: https://www.socialcomics.com.br

Recebido em: 04/07/2019

Aceito em: 11/09/2019 